\title{
THE EFFECTS OF FAMILY HISTORY AND PERSONAL EXPERIENCES OF ILLNESS ON THE INCLINATION TO CHANGE HEALTH-RELATED BEHAVIOUR
}

\author{
Per Andersson', Rickard L. Sjöberg², John Öhrvik², Jerzy Leppert ${ }^{2}$ \\ 'School of Health, Care and Social Welfare, Mälardalen University, Västerås, Sweden \\ ${ }^{2}$ Centre of Clinical Research, Uppsala University, Central Hospital, Västerås, Sweden
}

\begin{abstract}
SUMMARY
The aim of the present study was to examine how a personal experience of illness and a family history of cardiovascular disease (CVD), adjusted for sex, level of education and nationality, affect risk behaviour. Participants were 1,011 and 1,043, 50-year-old men and women from Sweden and Poland, respectively, who were recruited from a primary health care screening programme. Family history, personal experience of illness and risk behaviour (smoking and exercise habits, BMI level) were self-reported. The results showed that smoking behaviour was affected by a personal experience of illness but not by a family history of CVD. No effects of these variables were found on the remaining risk-related variables tested in this study. These results suggest that individuals with a personal experience of illness may be more inclined to change smoking behaviour than the average person. Smoking prevention strategies may therefore benefit from targeting this group in particular.
\end{abstract}

Key words: history, experience of illness, CVD, risk behaviour, obesity

Address for correspondence: P. Andersson, School of Health, Care and Social Welfare, Mälardalen University, S-72123 Västerås, Sweden. E-mail: per.andersson@mdh.se

\section{INTRODUCTION}

One important part of preventive public health work is to support a population's ability to translate knowledge about risk factors into healthy behaviour. In the individual, this ability is driven by, among other things, attitude and the confidence in their own capacity (1-3). But is an inclination to change behaviour also affected by the degree to which the individual perceives that he or she is at risk of illness?

Several theoretical models, such as the Health Belief Model (HBM) and Social Cognitive Theory (SCT), suggest that this may be the case (4-7). One example of how this assumption has been examined empirically is a study of 178 mostly well-educated women (8). It emerged that perceived susceptibility for illness, perceived severity of illness and knowledge about risk factors were predictors of behaviour preventing cardiovascular disease (CVD). The study indicated that women with a personal experience of treatment for high blood pressure were more inclined to appropriate health behaviour compared to others.

In addition to a personal experience of illness, a family history of illness is also a factor that could theoretically increase the perceived risk of illness (9). However, a longitudinal study of 3,590 young adults (18-30 years old) unexpectedly showed that the development of heart disease in a close relative was not motivation for long-lasting change in health behaviour (10).

Hence this may indicate that a personal experience, but not family history, of illness may have a strong effect on an individual's perception of the risk of illness, thus affecting behaviour. One possible explanation might be that the influence of family history on the perceived risk of illness is not strong enough to change behaviour. Results could furthermore have been influenced by the fact that participants were relatively young and may have had less inclination to perceive themselves as being at risk of disease in a general sense.

Other factors not examined in the above mentioned studies are how the level of education and nationality affect the correlation between the risk of illness and behaviour. A high level of education leads to healthier behaviour (11-13). The question is, however, whether it is the result of a high level of education in combination with a personal experience of illness and family history that contributes to healthier behaviour. For this reason, the aim of the present study was to further examine how a family history of cardiovascular disease and a personal experience of cardiovascular disease, adjusted for sex, education and nationality, affect risk behaviour.

\section{METHODS}

Study populations. This investigation was carried out using a screening programme specifically designed to study potential cardiovascular risk factors in 50-year-olds in the Polish city of Wroclaw and the Swedish county of Västmanland (14). Screening was organised by district nurses and also included verbal health information. The Polish data were collected between October 2000 and January 2001, and the Swedish data between May 1997 and April 1998. Wroclaw has a population of 640,000 inhabitants and is situated in Lower Silesia in South West Poland. The region of Wroclaw is highly industrialised and the city has one of the largest universities in the country. The Swedish county of 
Västmanland has a population of about 260,000 inhabitants. It is industrialised, and does not differ from other counties in central Sweden in terms of demographic factors (15).

Based on a model previously developed in Västmanland, the Wroclaw Health Department organised the screening procedure in Poland. There are 89 health care centres (HCC) of differing sizes and management structures in the region of Wroclaw. For this study, a total of ten HCCs were selected to participate. In the year 2000, these HCCs provided health-related services to 2,205 men and women aged 50, all of whom were sent an invitation to participate in the screening procedure. Of these individuals, 1,043 agreed (419 men and 624 women).

In the Swedish county of Västmanland data collection was conducted from May 1997 to April 1998, with 1,129 50-year-old individuals taking part in a health screening procedure performed in 34 out of a total of $36 \mathrm{HCCs}$. Of these individuals, 1,011 (90\%, 554 women and 457 men) completed the questionnaire. This was about half of the population of 50-year-olds in the county of Västmanland and Wroclaw, respectively, and thus also about half of those invited to participate in the health screening programme.

Questionnaires and screening analyses. A questionnaire similar to that utilised in an earlier study was used. It contains items pertaining to background variables (e.g. sex and level of education) as well as to knowledge about and attitudes to important risk factors for cardiovascular disease (CVD) $(14,16,17)$. The Polish screening form was developed from the one used in the Swedish study.

The screening analyses dealt with questions about life habits and health status. Smoking behaviour was classified into one of five categories (never smoked, ex-smokers, 1-14, 14-25 or $>25$ cigarettes/day) and in this study were dichotomised into current smokers and non-smokers. Physical exercise was assessed on a self-reported five-point scale (exercise daily, 3-4 times a week, 1-2 times a week, 1-2 times a month, seldom or never). This scale was dichotomised into those who exercised at most 1-2 times a week and those who exercised more often. Body Mass Index (BMI) was calculated as weight in kilograms $(\mathrm{kg})$ divided by height in metres squared $\left(\mathrm{kg} / \mathrm{m}^{2}\right)$. Weight was measured without shoes and with light clothing, and calculated to the nearest $0.1 \mathrm{~kg}$ on a balance beam scale. Standing height was measured with a fixed stadiometer calibrated in centimetres. In this study, BMI was dichotomised into $<30 \mathrm{~kg} / \mathrm{m}^{2}$ and $\geq 30 \mathrm{~kg} / \mathrm{m}^{2}$ (obesity).

Participants stated whether they had diabetes, were being treated for hypertension or were receiving hospital treatment for myocardial infarction or stroke. These individuals were dichotomised into whether or not they had a personal experience of illness. A family history of CVD was obtained from the self-report questionnaire. It contained dichotomous questions to ascertain whether or not the participants' parents had died or suffered from myocard infarction or stroke before the age of 55 (yes/no). Level of education was classified into low (a maximum of 12 years) and high (more than 12 years).

The regional human ethics committee (Uppsala University, Sweden) approved the Swedish study. The director of health authorities in the city of Wroclaw approved the Polish counterpart.

Statistical analyses. A personal experience of illness and a family history of CVD in relation to country, sex and level of education were presented as proportions and chi-square test was used for comparison of those non-parametric data. The gammatest was used as a measure of association between family history and a personal experience of illness. Multiple logistic regression was used to study the relationship between dichotomous responses and the following factors: smoking habits (non-smokers $=1$; current smokers $=0$ ), exercise habits (regularly $=1$, seldom $/$ never $=$ 0 ) and actual BMI level (BMI $<30 \mathrm{~kg} / \mathrm{m}^{2}=1$, BMI $\geq 30 \mathrm{~kg} / \mathrm{m}^{2}=$ 0 ). The analyses were adjusted for country, sex and level of education if applicable $(p<0.05)$. First-order interaction terms were also tested for possible inclusion $(\mathrm{p}<0.10)$. The significance level was $5 \%$ (two-sided) except for interaction analyses, where the significance level (two-tailed) was $\mathrm{p}<0.1$.

\section{RESULTS}

Of all participants, $21 \%(\mathrm{n}=424)$ had a family history of CVD (Table 1), of whom considerably more were Polish (27\%) than Swedish $(14 \%)(\mathrm{p}<0.002)$. There was an even distribution between men and women with one exception: considerably more highly educated Polish women (28\%) than men (22\%) ( $\mathrm{p}=0.206)$ had a family history of CVD.

Of all participants, $19 \%(n=388)$ had a personal experience of CVD (Table 2), of whom considerably more were Polish (27\%) than Swedish $(10 \%)(p<0.001)$. Among both nationalities, those with a lower level of education had experienced CVD to a greater extent than those with a higher level of education (Poland 29\% versus $23 \%, \mathrm{p}=0.02$; Sweden $12 \%$ versus $5 \%, \mathrm{p}=0.003$, respec-

Table 1. Demographic data for family history of CVD, related to nationality, level of education and sex

\begin{tabular}{|c|c|c|c|c|c|c|c|}
\hline \multirow[b]{2}{*}{$\begin{array}{l}\text { Level of } \\
\text { education }\end{array}$} & \multirow[b]{2}{*}{ Family history } & \multicolumn{2}{|c|}{ Sweden } & \multicolumn{2}{|c|}{ Poland } & \multirow[t]{2}{*}{$\mathrm{p}$-value } & \multirow{2}{*}{$\begin{array}{c}\text { Total } \\
\%(n=530)\end{array}$} \\
\hline & & $\begin{array}{c}\text { Men } \\
\%(n=96)\end{array}$ & $\begin{array}{c}\text { Women } \\
\%(n=129)\end{array}$ & $\begin{array}{c}\text { Men } \\
\%(n=140)\end{array}$ & $\begin{array}{c}\text { Women } \\
\%(n=165)\end{array}$ & & \\
\hline \multirow{2}{*}{ High } & Yes & 14 & 16 & 22 & 28 & \multirow{2}{*}{0.002} & 21 \\
\hline & No & 86 & 84 & 78 & 72 & & 79 \\
\hline & & $\%(n=354)$ & $\%(n=411)$ & $\%(n=277)$ & $\%(n=457)$ & & $\%(n=1499)$ \\
\hline \multirow{2}{*}{ Low } & Yes & 14 & 14 & 26 & 28 & \multirow{2}{*}{$<0.001$} & 21 \\
\hline & No & 86 & 86 & 74 & 72 & & 79 \\
\hline
\end{tabular}

$\mathrm{p}=$ difference between Swedish and Polish male and female. 
Table 2. Demographic data for personal experience of illness, related to nationality, level of education and sex

\begin{tabular}{|c|c|c|c|c|c|c|c|}
\hline \multirow[b]{2}{*}{$\begin{array}{l}\text { Level of } \\
\text { education }\end{array}$} & \multirow[b]{2}{*}{$\begin{array}{l}\text { Experience } \\
\text { of illness }\end{array}$} & \multicolumn{2}{|c|}{ Sweden } & \multicolumn{2}{|c|}{ Poland } & \multirow[t]{2}{*}{$\mathrm{p}$-value } & \multirow{2}{*}{$\frac{\text { Total }}{\%(n=532)}$} \\
\hline & & $\begin{array}{c}\text { Men } \\
\%(n=97)\end{array}$ & $\begin{array}{c}\text { Women } \\
\%(n=130)\end{array}$ & $\begin{array}{c}\text { Men } \\
\%(n=140)\end{array}$ & $\begin{array}{c}\text { Women } \\
\%(n=165)\end{array}$ & & \\
\hline \multirow{2}{*}{ High } & Yes & 8 & 3 & 26 & 21 & \multirow{2}{*}{$<0.001$} & 15 \\
\hline & No & 92 & 97 & 74 & 79 & & 85 \\
\hline & & $\%(n=355)$ & $\%(n=420)$ & $\%(n=277)$ & $\%(n=457)$ & & $\%(n=1509)$ \\
\hline \multirow{2}{*}{ Low } & Yes & 10 & 13 & 29 & 30 & \multirow{2}{*}{$<0.001$} & 20 \\
\hline & No & 90 & 87 & 71 & 70 & & 80 \\
\hline
\end{tabular}

$\mathrm{p}=$ difference between Swedish and Polish male and female

tively). Similarly, more of the highly educated individuals with an experience of illness were men (Poland, men $26 \%$ versus women $21 \%, \mathrm{p}=0.290$ ); Sweden, men $8 \%$ versus women $3 \%, \mathrm{p}=0.151$ ). However, among those with a lower level of education, the sex difference for experience of illness was marginal (Poland, men $29 \%$ versus women $30 \%, \mathrm{p}=0.721$; Sweden, men $10 \%$ versus women $13 \%, \mathrm{p}=0.342$ ).

There was a statistically significant correlation between family history and a personal experience of illness, however, it was only moderate $\left(\chi^{2}=15.481\right.$, gamma $\left.0.248, p<0.001\right)$.

The results showed increased odds for those with a personal experience of illness to be non-smokers than for those without an experience of illness. This was adjusted for family history, sex, level of education and nationality (Table 3). A family history of CVD, adjusted for experience of illness, sex, level of education and nationality, did not lead to healthier smoking behaviour. The odds ratios $(\mathrm{OR})$ for experience of illness $(\mathrm{OR}=1.48,95 \% \mathrm{CI}=$ $1.14-1.93)$ and family history $(\mathrm{OR}=0.84 ; 95 \% \mathrm{CI}=0.66-1.07)$ in relation to smoking behaviour (including $95 \% \mathrm{CI}$ ) did not overlap. This indicates that experience of illness influences smoking behaviour to a higher degree than family history.

Family history and personal experience of CVD were not predictors of more physical exercise. Swedish participants had increased odds $(\mathrm{OR}=2.82,95 \% \mathrm{CI}=2.22-3.59)$ of exercising regularly compared to Polish individuals (adjusted for experience of illness, family history, sex and level of education). This demonstrates an interaction effect for experience of illness and nationality, i.e. there were increased odds of exercising more seldom for Polish than Swedish participants with a personal experience of illness.

Furthermore, the results show that those participants with an experience of illness and a family history of CVD were to a greater extent obese than those without it (adjusted for sex, nationality and level of education). Polish individuals had increased odds of being obese compared with Swedish nationals, and more men than women were extremely overweight. When analysing interaction effects of family history and nationality, participants with a family history of CVD from Poland were to a greater extent obese than those from Sweden. In addition, the odds of being obese were greater among men than women for participants with a family history of CVD.

\section{DISCUSSION}

The aim of the present study was to examine how a personal experience of illness and a family history of CVD affect risk behaviour. The results, adjusted for sex, education level and nationality, showed that smoking behaviour was influenced by a personal experience of illness but not by a family history of CVD. Neither had any significant effects on other health- and behaviour-related outcomes studied.

The finding that a personal risk of illness will lead to healthier smoking behaviour can theoretically be explained by the Health Belief Model (HBM), according to which the perception of vulnerability contributes to healthier behaviour (18). To be a smoker, diabetic or to receive treatment for high blood pressure probably constitutes a warning signal, and thus increases the perception of the personal risk of illness.

In obese individuals, the experience of earlier illness is not a sufficiently strong threat to try and normalise their weight. On the contrary, it increases the odds of being obese. A personal experience of illness and being overweight ought to involve a desire to change behaviour, but according to the results of this study this is not the case. According to an earlier study among overweight patients with CVD, low self-efficacy explained why obese individuals did not change their behaviour (19). The study participants were invited to undergo medical examination and probably did not perceive an increased personal risk of illness to the same extent as individuals with CVD. However, low self-efficacy could explain why obese people do not engage in healthier behaviour. The correlation between a personal risk of illness and self-efficacy has been previously studied and it has been shown that self-efficacy has a strong effect on behaviour and change of behaviour despite a personal risk of illness (20). According to the results of this study, a family history of illness did not predict healthier behaviour. When a close relative falls ill, it might be assumed that a family member would try to adopt a healthier behaviour in order to avoid the same illness. Earlier studies showed that the behaviour of young adults (18-30 years old) changes in close connection with the illness of a parent, but that this change is not permanent (10). One conceivable explanation may be that a family history of CVD is not experienced as a sufficiently strong threat. Previous observations furthermore suggest that a history of cancer in a family may be perceived as more threatening than of CVD (9). Thus, the lack of understanding of a family history 
Table 3. The influence of adjusted experience of illness (reference $=$ no experience of illness) and family history (reference = no family history) of CVD on smoking (event $=$ non-smoker), exercise habits (event $=$ regular exercise) and obesity (event $=$ non-obese), including first order interactions

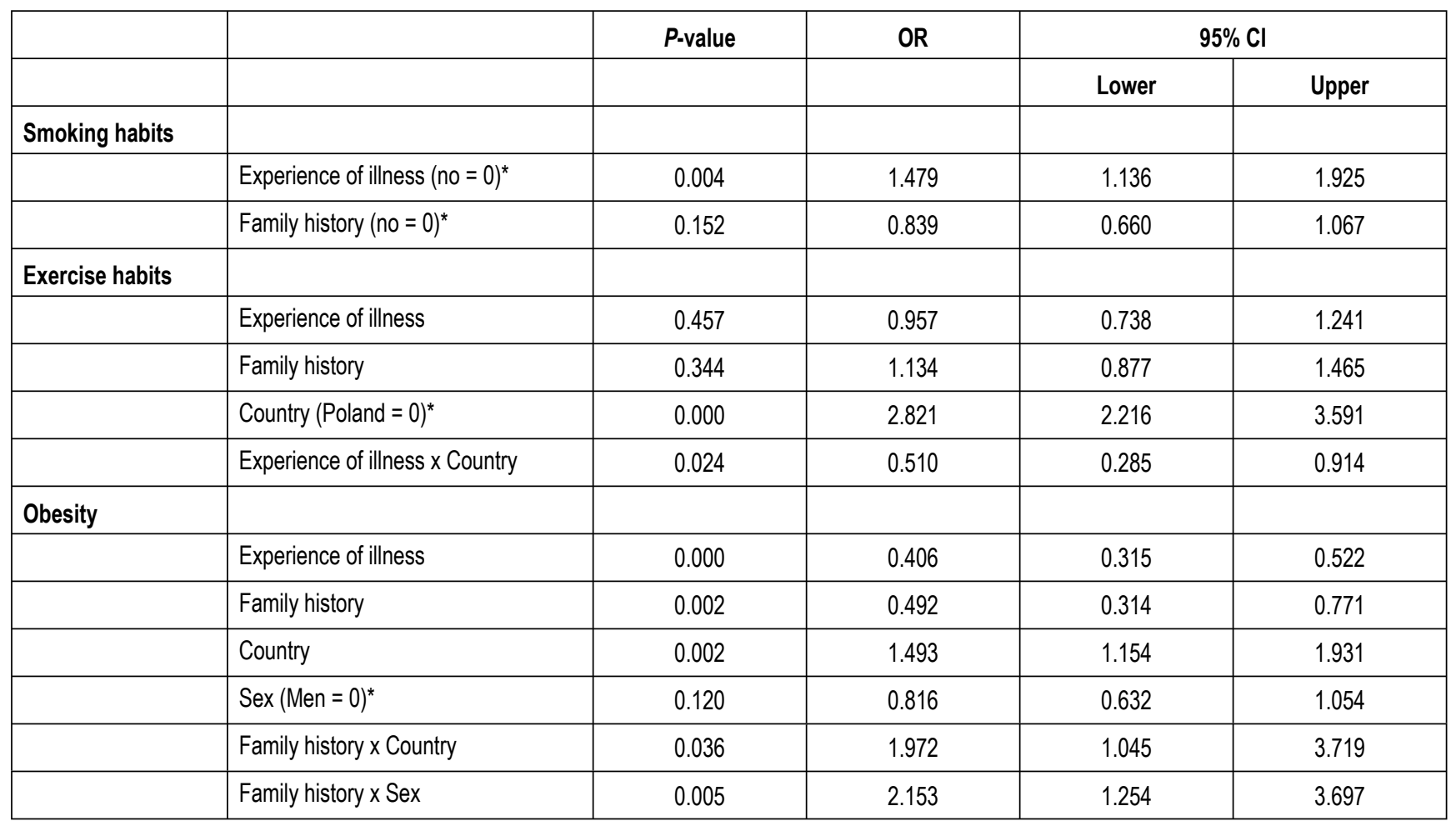

${ }^{*}$ Reference category

of CVD as a risk factor could explain why individuals with such a family history do not engage in healthier behaviour $(21,22)$.

The data presented in this study were correlational, which means that conclusions regarding the direction of cause and effect must be considered tentative. Another limitation of the present study was the relatively high proportion of individuals who chose to not participate in the health screening. Earlier studies, however, including a drop-out analysis performed in the same area of Sweden on a similar intervention, have shown similar results comparing non-participants and participants (23-25). A strength of the present study was the adjustment of results for sex, level of education and nationality. The latter appeared to be a factor that correlated with a risk behaviour, a condition that has been corroborated in previous studies $(14,26)$. Another strength was that the study was population-based which may have avoided selection bias inherent in clinical samples.

One conclusion of this study is that individuals with a personal experience of illness may be more inclined to change smoking behaviour than the average person. This suggests that health prevention strategies may benefit from focusing on this group in particular.

\section{REFERENCES}

1. Rimal RN. Closing the knowledge-behavior gap in health promotion: the mediating role of self-efficacy. Health Commun. 2000;12(3):219-37.

2. O'Hea EL, Boudreaux ED, Jeffries SK, Carmack Taylor CL, Scarinci IC, Brantley PJ. Stage of change movement across three health behaviors: the role of self-efficacy. Am J Health Promot. 2004 Nov-Dec;19(2):94-102.

3. King TK, Marcus BH, Pinto BM, Emmons KM, Abrams DB. Cognitive-behavioral mediators of changing multiple behaviors: smoking and a sedentary lifestyle. Prev Med. 1996 Nov-Dec;25(6):684-91.

4. Whitehead D. A social cognitive model for health education/health promotion practice. J Adv Nurs. 2001 Nov;36(3):417-25.

5. Janz NK, Becker MH. The Health Belief Model: a decade later. Health Educ Q. 1984 Spring;11(1):1-47.

6. Bandura A. Health promotion by social cognitive means. Health Educ Behav. 2004 Apr;31(2):143-64.

7. Janz NK. The Health Belief Model in understanding cardiovascular risk factor reduction behaviors. Cardiovasc Nurs. 1988 Nov-Dec;24(6):39-41.

8. Ali NS. Prediction of coronary heart disease preventive behaviors in women: a test of the health belief model. Women Health. 2002;35(1):83-96.

9. Walter FM, Emery J. Perceptions of family history across common diseases a qualitative study in primary care. Fam Pract. 2006 Aug;23(4):472-80.

10. Kip KE, McCreath HE, Roseman JM, Hulley SB, Schreiner PJ. Absence of risk factor change in young adults after family heart attack or stroke: the CARDIA Study. Am J Prev Med. 2002 May;22(4):258-66.

11. Mayer O Jr, Simon J, Heidrich J, Cokkinos DV, De Bacquer D; EU ROASPIRE II Study Group. Educational level and risk profile of cardiac patients in the EUROASPIRE II substudy. J Epidemiol Community Health. 2004 Jan;58(1):47-52

12. Strand BH, Tverdal A. Can cardiovascular risk factors and lifestyle explain the educational inequalities in mortality from ischaemic heart disease and from other heart diseases? 26 year follow up of 50,000 Norwegian men and women. J Epidemiol Community Health. 2004 Aug;58(8):705-9.

13. Kilander L, Berglund L, Boberg M, Vessby B, Lithell H. Education, lifestyle factors and mortality from cardiovascular disease and cancer. A 25-year follow-up of Swedish 50-year-old men. Int J Epidemiol. 2001 Oct;30(5):1119-26.

14. Andersson P, Sjöberg RL, Krysa M, Sidorowicz W, Ohrvik J, Leppert J. Lags in behavioral change: a population based comparison of cardiovascular risk behavior in Poland and Sweden. Cent Eur J Public Health. 2006 Jun; 14(2):82-5.

15. Risk factors in coronary heart diseases - regional and social disparity in Sweden. EpC report no. 99-1922035-3;1997:1. Stockholm: Socialstyrelsen; 1997. (In Swedish.)

16. Osler M, Lous J, Rasmussen NK. A study of citizens' prevention of coronary heart diseases in Vejle. Copenhagen: Danish Institute for Clinical Epidemiology; 1989. (In Danish.) 
17. Andersson P, Leppert J. Men of low socio-economic and educational level possess pronounced deficient knowledge about the risk factors related to coronary heart disease. J Cardiovasc Risk. 2001 Dec;8(6):371-7.

18. O’Connell JK, Price JH, Roberts SM, Jurs SG, McKinley R. Utilizing the Health Belief Model to predict dieting and exercising behaviour of obese and nonobese adolescents. Health Educ Q. 1985 Winter;12(4):343-51.

19. Sol BG, van der Graaf Y, van der Bijl JJ, Goessens NB, Visseren FL. Self-efficacy in patients with clinical manifestations of vascular diseases. Patient Educ Couns. 2006 Jun;61(3):443-8.

20. Rimal RN. Perceived risk and self-efficacy as motivators: understanding individuals' long-term use of health information. J Commun. 2001 Dec;51(4):633-54.

21. Watt G, McConnachie A, Upton M, Emslie C, Hunt K. How accurately do adult sons and daughters report and perceive parental deaths from coronary disease? J Epidemiol Community Health. 2000 Nov;54(11):859-63.

22. McCusker ME, Yoon PW, Gwinn M, Malarcher AM, Neff L, Khoury MJ. Family history of heart disease and cardiovascular disease risk-reducing behaviors. Genet Med. 2004 May-Jun;6(3):153-8.
23. Weinehall L, Hallgren CG, Westman G, Janlert U, Wall S. Reduction of selection bias in primary prevention of cardiovascular disease through involvement of primary health care. Scand J Prim Health Care. 1998 Sep;16(3):171-6.

24. Persson LG, Lindström K, Lingfors H, Bengtsson C. A study of men aged 33-42 in Habo, Sweden with special reference to cardiovascular risk factors. Design, health profile and characteristics of participants and non-participants. Scand J Soc Med. 1994 Dec;22(4):264-72.

25. Tibblin G. A population study of 50-year-old men. An analysis of the non-participation group. Acta Med Scand. 1965 Oct;178(4):453-9.

26. Johansson J, Viigimaa M, Jensen-Urstad M, Krakau I, Hansson LO. Risk factors for coronary heart disease in 55- and 35-year-old men and women in Sweden and Estonia. J Intern Med. 2002 Dec;252(6):551-60.

Received June 27, 2008 Accepted September 2, 2008 